should be put on the teaching of abstract concepts such as linear spaces, linear operators, convergence in metric spaces and group invariances and symmetries, even if the immediate practical applications were not fully described.

Comments on practical work were remarkable for the diversity of ideas revealed. S. C. Brown (Massachusetts Institute of Technology) claimed that the main object was to teach what a physicist does. Systematic experiments and laboratory reports should therefore be abandoned in favour of project work, closely linked with the research programme of the department. It was suggested that only the 2,000 physics students at Massachusetts Institute of Technology could ever enjoy such lavish attention, but Brown roported that most of the forwardlooking universities in the Unitod States used the same method. Some speakers thought that practical physics could be taught in lectures, though manipulative skill could only be acquired by experience at the bench. E. Mendoza (University of Wales) and F. H. Read (University of Manchester) favoured seminars in which a class (of up to fifty students) conducted one experiment under the guidance of a lecturer.

However great the importance of mathematical and practical instruction, the core of the undergraduate cur- riculum is in the systematic lectures by which the principles and applications of the subject are uncovered. The burdens laid on the undergraduate's knowledge and on his maturity of understanding are augmented every year. A. B. Pippard showed, from a study of examination papers, how to-day's student is expected to know just as much about electricity, thermodynamics and other longestablished divisions of physics as his counterpart of 1940 - and in addition, to be conversant with many newer topics of a substantial kind. His solution was to reduce the first-degree course to two years and to provide a more comprehensive training for a proportion of the student body.

The conference passed a number of resolutions of an unexciting character, but its real significance was based on divergence rather than unanimity. Physicists are produced with evident success in educational systems sufficiently varied to include strict Government control of priorities and syllabuses in the U.S.S.R., unfettered academic enterprise in the United States and the amalgam of tradition and innovation characteristic of both the older and newer British universities. The competence and enthusiasm of the finished products encourage the belief that the confusion over aims and methods is superficial.
J. M. A. LeniHAN

\title{
PLANT PHYSIOLOGY IN CANADA
}

$\mathrm{T}$ HE annual scientific and business meeting of the Canadian Society of Plant Physiologists-La Société Canadienne de Physiologie Végétale - was held at the University of New Brunswick, Fredericton, during June 2-5.

The programme commenced with a symposium entitled "Problems in Marine Algal Physiology". J. S. Craigie (N.R.C., Halifax) discussed the problems of isolat. ing and identifying marine algal excretory products from sea-water. Compounds excreted by several brown and red algae were identified as condensed polyphenolic substances with distinct growth-promoting properties. A brominated benzyl alcohol derivative excreted by Polysiphonia lanosa was isolated and crystallized. A pure crystalline extracellular chitin excreted by the diatom Thalassiosira fluviatilis was isolated and characterized and was claimed to be the first recorded evidence for the occurrence of poly- $N$-acetyl glucosamine in the algae. L. Provasoli (Haskins Laboratories, New York) discussed the nutritional requirements of marine algae grown aseptically. Unlike unicellular algae, seaweeds grown autotrophically require a range of vitamins in specific concentrations and ratios for normal morphological development. The growth of Ulva and Monostroma in aseptic culture was maintained only in the presence of plant hormones, phenolic compounds, and by the addition of supernatants containing active substances from a variety of red and brown seaweeds and from several unicellular algae grown aseptically on artificial media. These unidentified active substances are ethanol extract. able and heat resistant and their ubiquitous production in the sea underlies the significance of external metabolites in the water environment. R. T. Wilce (Amherst, Massachusetts) discussed algal survival in the Arctic Sea. Reproductive activity at the end of the winter period and an abundant spring and summer growth were found to depths of 30 metres. The greatest concentration of algal biomass occurred at 15-20 metres, where extremely low light intensities were recorded. Survival under these conditions requires either the possession of a highly efficient photosynthetic apparatus or the facility to exist heterotrophically. Evidence for the heterotrophic growth of pigmented algae in deep lakes and unlit caves suggested that these arctic populations also thrived by the heterotrophic utilization of organics from the sea.

Several scientific sessions followed the symposium. Continuing their work on plant photorespiration, G. Krotkov et al. (Queens, Kingston) showed a distinction in spruce tissue between photo- and dark-respiration with the latter inhibited by light. W. Turner and R. G. S. Bidwell (Toronto) presented evidence for the enhancement of assimilation of carbon dioxide by leaf blades with application of IAA. E. R. Waygood et al. (Manitoba), working with detached wheat leaves, showed that photophosphorylation could be both restored and enhanced by benzimidazole treatment and that the synthetic pathway of NAD and NADP from ${ }^{14} \mathrm{C}$-carbonyl-nicotinic acid was essentially the same as that reported for animal tissues and micro-organisms. The permanent bleaching of Euglena gracilis by nitrofuran derivatives was discussed by D. R. McCalla (McMaster, Hamilton). Other mutagens and radio-mimetic agents were used as bleaching agents, but only $N$-methyl- $N$-nitroso guanidine proved nonlethal. It was suggested that these bleaching agents damaged chloroplast DNA. Continued interest in the biosynthesis of aromatic compounds and phenolase enzyme systems was reported by A. C. Neish et al. from the Atlantic Regional Laboratory (N.R.C., Halifax). In particular the biosynthesis of the cinnamic acid derivatives as the $\mathrm{C}_{6}-\mathrm{C}_{3}$ intermediates in lignin formation was discussed. Other biochemical contributions of interest dealt with the in vitro synthesis of glycine and the metabolic utilization of ${ }^{14} \mathrm{C}$-ethanol (E. A. Cossins et al., Alberta). N. E. Good (Michigan) discussed the preparation of several new $\mathrm{H}$ ion buffer systems. They were mostly substituted derivatives of tris(hydroxymethyl)amino methane covering the $p \mathrm{H}$ range from 6 to 8 and were claimed to be superior to both tris and phosphate buffers.

Several contributions described studies of the structure and the effects of environment on plant cells by electron microscope and light microscope. A. J. Mia and G. Setterfield (Carleton, Ottawa) reported the synthesis of cell wall material by apposition in Rauwolfia sclereids using ${ }^{3} \mathrm{H}$-glucose pulse labelling. In a session on translocation in the higher plants, contributions from the Biosciences Division (N.R.C., Ottawa) described the experimental 
control of ${ }^{14} \mathrm{C}$-sugar movement by changing the node temperature (J. A. Webb and P. R. Gorham), and discussed the distinct lack of evidence demonstrating sugar conduction in the sieve tubes (D. C. Mortimer and M. Suzuki). D. S. Fonsom and D. C. Spanner (London, England) reported their measurements of microelectrode potentials in the conducting tissue of Nymphoides and Heracleum and calculated that the electro-osmotic efficiency was sufficient to maintain sugar flow through partially blocked siove plate pores.

In a final session on plant growth substances, several contributions were concerned with the influenco of exogenously supplied gibberellins and IAA on plant development. Three reports discussed tho interesting problems of IAA conjugation in plant tissues. E. Schneider and F. Wightman (Carleton, Ottawa) showed IAA $-2-{ }^{14} \mathrm{C}$ to be metabolized mainly through conjugation to indoleacetyl aspartic acid, indoleacetyl glucose and 2-OH indoleacetylglucose in barloy seedlings over a 24-h period. A. Winter and K. V. Thimann (Harvard University), however, could find no evidence for conjugate compounds over a 2-h period in Avena coleoptiles and con- sidered fed ${ }^{14} \mathrm{C}-\mathrm{IAA}$ to be physically bound to a protein fraction. N. A. Andreae (Department of Agriculture London) showed that conjugate products were formed with IAA inactivation, when pea roots were pretreated with an excess of IAA and NAA. An adaptive period of 2-4 h was necessary before the conjugate products were discerned. 2,4-D was not conjugated and remained inhibitory regardless of the pretreatment time. J. I. Toohey and C. D. Nelson (Queens, Kingston) reported two new herbicides derived from a soil bacterium inhabiting old pastures. The compounds were toxic to algae and higher plants but not to insects, fish or mammals. They were isolated and identified as phenazine-1-carboxylic acid (most toxic to higher plants) and the 2-OH derivative (most toxic to the algae).

Officers of the society elected for $1965-66$ were: President, Dr. G. H. N. Towers (Univorsity of British Columbia); Vice-president, Dr. D. Simminovitch (Department of Agriculture, Ottawa); Secretary-treasurer, Dr. D. Canvin (Queens, Kingston); Eastern director, Dr. A. R. A. Taylor (University of New Brunswick); Western director, Dr. M. S. Spencer (University of Alberta). J. A. WEBB

\section{A REGISTER OF SCIENTIFIC RESEARCH IN THE NETHERLANDS}

$\mathrm{I}^{\mathrm{N}}$ 1964 the Netherlands Organization for the Advancement of Pure Research (Z.W.O.) began a register of scientific research in the Netherlands. The results of this work are to be published in the form of a periodical guide giving details of current scientific investigations. The purpose of this guido is to foster contact between research scientists. It supplies both Dutch and foreign scientists with information on the research being carried out in the Netherlands. With the view of foreign readership it appears in English.

For recent scientific information the research scientist must depend either on personal contacts or on articles in journals, reports, otc. In the case of leading scientists such as university professors working in small and highly specialized fields, personal contact often provides sufficient communication; however, this is much loss true of their staff. As regards research scientists in larger and above all multi-disciplinary fields, personal contact usually satisfies only a small part of the need for communication.

So far as journals, reports, etc., are concerned, not only does it take a long time until the original publications are reported in abstracting journals, but also there is a considerable interval before the results of a research project are published. Moreover, the research scientists concerned may have information available long before then. It may also be remarked that a great deal of research is never published, for a varioty of reasons, for examplo in the event of discontinuance of the project; valuable information may be lost in this way.

The marked expansion of research at the universities makes it still more desirable that the need for recent scientific information be satisfied. The guide contributes towards this by presenting research scientists with a basis on which further contacts can be established.

The guide has been inspired by the British publication Scientific Research in British Universities and Colleges, published by the Department of Scientific and Industrial Research and the British Council; this gives concise information on scientific research in Great Britain *.

At first there was some doubt about the value of this publication in Britain, but in the course of the years its utility has been clearly proved. Consequently, Z.W.O. decided to build up experience by starting in one field and

* Now published by the Department of Education and Science and the British Council (Nature, 207, 691; 1965). submitting the result to scientists for discussion; physics was chosen as this first field.

In principle the guide only mentions research projects by or under the direct control of professors, lecturers and scientific staff.

Taking into account the purpose of the guide, preference was givon to a main grouping by subject rather than by university department. As researeh scientists are best served by a classification that they already know, it was decided to follow the leading abstracting journal for each field of science. As the register is extended to more fields the disadvantage will have to be accepted of a certain lack of balance as compared with a general classification, such as the Universal Decimal Classification, which was dovised as a whole.

For physics, Physics Abstracts, published by the Institution of Electrical Engineers, London, has been chosen. The research seientist was asked to classify his research project under one of the eightoen headings of Physics Abstracts. In order to reduce discrepancies to a minimum, a copy of the classification followed by this journal was attached to the questionnaire.

In the guide the research projects are arranged under the afore-mentionod headings of Physics Abstracts. Within these groups there is a sub-division according to the institution where the research is being carried out. Besides a name index and a subject indox, a list of cooporating research institutes, with their addressos, is given.

Before questionnaires were sent out, the arrangement was submitted to the chairmen of the physics departments of the various universities. The idea of this was to obtain their criticism in good time, so that allowance could be made for it in the questionnaire; most of them also proved ready to call on the co-operation of the professors and lecturers to be covered by the survey.

The questionnaire was kept simple so that filling it in would not take up too much of the scientist's time. Only those questions wore asked which are directly connected with the three questions which the guide trios to answer, namely: (1) What kind of research is being done? (2) Who is doing it? (3) Where is it being done?

To every professor and lecturer of physics were sent 5-10 questionnaires on which to report the relevant research; in most cases they were sent direct, though in 